\title{
Evaluation of the effects of iron containing supplements on primary teeth of children
}

\author{
Eda Arat Maden ${ }^{1}$, İbrahim Eker ${ }^{\oplus}$, Onur Erdem ${ }^{3}$ \\ ${ }^{1}$ Şişli Hamidiye Etfal Training and Research Hospital, Department of Pediatric Dentistry, Istanbul, Turkey. \\ ${ }^{2}$ Afyon Kocatepe University, Faculty of Medicine, Department of Paediatric Hematology, Afyon, Turkey. \\ ${ }^{3}$ Health Sciences University, Department of Pharmaceutical Toxicology, Ankara, Turkey.
}

\section{Correspondence:}

\section{Dr. Eda ARAT MADEN}

Şișli Hamidiye Etfal Training and Research Hospital, Department of Pediatric Dentistry, Istanbul, Turkey

E-mail:edamaden1980@gmail.com

Received: 13 July 2018

Accepted: 8 May 2019

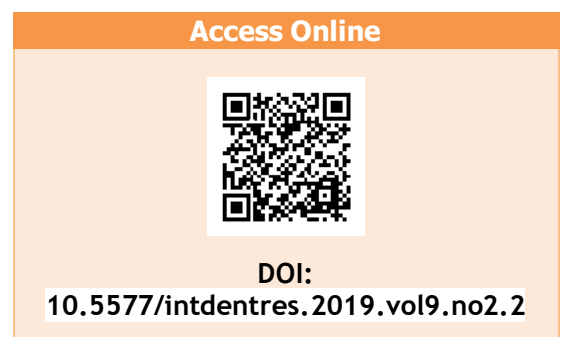

\section{Introduction}

Tooth caries are one of the most occuring infectious diseases globally. The definition of Early Childhood Caries (ECC) is a broad one which is used for all kinds of caries in primary dentition in children 71 months or younger. The definition of Severe Early Childhood Caries (S-ECC) is the existence of any type of

\section{Abstract}

Aim: Extrinsic tooth staining potential of iron replacement therapy causes a belief among the parents that these drugs cause tooth decay. In order to clarify this suspicion, the relationship between iron replacement therapy, dental iron concentrations and tooth decay was examined.

Methodology: The study was carried out on 21 children, whose age were between 5 and 12 years and had gone through primary teeth extraction process. The children were evaluated for caries, missing and filling index (DMFT). The parents' of the children were asked to fill out a questionnaire that included questions about whether their children were receiving iron replacement therapy during their infancy. The iron levels in the samples were measured by atomic absorption spectrophotometer and the results were evaluated statistically.

Results: There was no significant difference between the DMFT score of children who received regular iron replacement during infancy and who did not receive. There was not a statistically significant difference between the median iron concentration in the primary teeth of the children who were supplemented with iron in their toddler's age $(10,5 \mathrm{mikrog} / \mathrm{gr}(5,3-$ $17,3))$ and were not supplemented $(5,6 \mathrm{mikrog} / \mathrm{gr}(0,64-48,9))$.

Conclusions: The results of the study showed that iron replacement had no adverse effect on the primary teeth.

\section{Keywords: Dental caries, iron, supplementation, toddler}

How to cite this article: Arat Maden E, Eker İ, Erdem O. Evaluation of the Effects of Iron Containing Supplements on Primary Teeth of Children. Int Dent Res 2019;9(2):46-50. 
deficiencies may have negative effects on cognitive functions (1). About six months old babies are at risk of developing iron deficiency anemia as a result of depletion of iron deposits required for rapid growth. The rate of iron in mother's milk is very low (2). Therefore, various organizations propose medical iron supplements to meet the iron needs of infants $(3,4)$.

A common side effect of iron supplementation in liquid form is that it causes teeth stains. There is a legend among parents about the linking of iron with risk of tooth decay, which arose from the staining of their children's teeth after iron therapy. As a result, this fear of the parents causes deprivation of the iron therapy (5). Most of the literatures searching the relation of iron and tooth decay are animal studies (6-9). Hereby, the relation of iron supplementation and dental iron concentrations with tooth caries in children was evaluated in the current study to clarify this doubt and to prevent unnecessary deprivation of this important supplementation therapy of iron.

\section{Materials and Methods}

The study was carried out on 21 children, whose ages were between 5 and 12 years and had gone through primary teeth extraction process. They were admitted to Training and Research Hospital, Oral and Dental Health Center for the extraction of primary tooth. After their oral and dental health examination decayed, missing, and filled teeth (DMFT) index were evaluated and recorded. Also, their parents were asked to complete a questionnaire including the risk factors of their children for tooth decay, the period of iron supplementation therapy in the children's toddler age and in the mothers' pregnancy. After extraction the primary teeth, were placed into polypropylene tubes, containing sodium chloride solution. The iron concentrations in the primary teeth of children were estimated using atomic absorption spectrophotometer at University of Science Health, Department of Pharmaceutical Toxicology.

Ethical clearance was obtained and all necessary ethical guidelines were followed pursuant to the Institutional Ethical Committee and in accordance with the Central Ethics Committee on Human Research, Turkey.

\section{Statistical Analysis}

Analysis of data was carried out using Statistical Program for Social Science (SPSS Inc., Chicago, IL, USA) version 11,5 (Licensed SPSS program of University of Science Health). Quantitative variables were described in the form of median (minimum-maximum). Qualitative variables were described as number and percent. In order to compare parametric quantitative variables between two groups, Student's t-test was applied. Comparison between categorical variables was performed using chi-squared (v2) test. Spearman's rank correlation coefficient and multiple regression analysis were employed to assess the relationship between quantitative variables. $p$ value $<0.05$ was considered significant.

\section{Results}

There were 14 females $(66,7 \%)$ and 7 (33\%) males children. $90 \%$ of the children's mothers were supplemented with iron therapy during their pregnancy and the remaining $10 \%$ were not. $76,2 \%$ of the children received iron therapy for supplementation regularly in toddler's age and the others were not supplemented or did not receive it regularly. The median DMFT score of the children were 2,5 (0-10) in females and $3(0-7)$ in males and there was not a statistically significant difference. The median DMFT score of the children, whose mothers' supplemented with iron in their pregnancies were 2,5 (0-10) and whose mothers' were not supplemented were 5 (3-7) and again there was not a statistically significant difference. The median DMFT score of the children, who were supplemented with iron in their toddler's age were $3(0-10)$ and who were not supplemented were $0(0-3)$ and again there was not a statistically significant difference (Table 1 ).

The median iron concentration in the primary teeth of female children was 5,5 mikrog/gr $(0,64-48,9)$ and in the the primary teeth of male children, it was $9,8 \mathrm{mikrog} / \mathrm{gr}(1,5-46,8)$ and there was not a statistically significant difference among them.

The median iron concentration in the primary teeth of the children, whose mothers' were supplemented with iron in their pregnancies were 6,6 mikrog/gr $(1,5-48,9)$ and whose mothers' were not supplemented were $23,7 \mathrm{mikrog} / \mathrm{gr}(0,6-46,8)$ and there was not a statistically significant difference. The median iron concentration in the primary teeth of the children, who were supplemented with iron in their toddler's age were 10,5 mikrog/gr $(5,3-17,3)$ and who were not supplemented were 5,6 mikrog/gr $(0,64$ $48,9)$ and again there was not a statistically significant difference (Table 1).

There was a significant negative correlation between the mother's age and the DMFT score of the children $(r=-0,445 ; p=0,043)$. There was a significant negative correlation between the age of the children and the iron concentration in the primary teeth and also between the weight and the iron concentration of the primary teeth $(r=-0,445 ; p=0,043$ and $r=-0,877$; $p<0,001$ respectively). There was a negative, but not significant correlation between the iron concentration in the primary teeth and the DMFT score $(r=-0,124 ; p=$ 0,593) (Table 2). 
Table 1. DMFT scores and iron concentrations of iron supplemented children and not supplemented children

\begin{tabular}{lccc}
\multicolumn{1}{c}{ Parameter } & $\begin{array}{c}\text { Iron supplemented } \\
\text { children }\end{array}$ & $\begin{array}{c}\text { Not supplemented } \\
\text { children }\end{array}$ & p value \\
DMFT score & 3 & 0 & NS \\
Median (Minimum-Maximum) & $(0-10)$ & 5,6 & NS \\
Iron concentration (mikrog/gr) & 10,5 & $(0,64-48,9$ & \\
Median (Minimum-Maximum) & $(5,3-17,3)$ &
\end{tabular}

NS: Non significant

Table 2: Correlation analysis between DMFT score of the children and the iron concentration in their primary teeth and their mother's age

\begin{tabular}{|c|c|c|c|}
\hline & & $\begin{array}{l}\text { The iron concentration in } \\
\text { their primary teeth }\end{array}$ & The mother's age \\
\hline \multirow{2}{*}{$\begin{array}{l}\text { DMFT score of the } \\
\text { children }\end{array}$} & $r^{*}$ & $-0,124$ & $-0,445$ \\
\hline & $p$-value & 0,593 & 0.043 \\
\hline
\end{tabular}

*: Correlation coefficient

\section{Discussion}

Iron deficiency (ID) is the most common single nutrient deficiency and may affect up to 20\% of children aged 1-3 years in Europe (10). This is highly concerning because it is clinically established that iron deficiency has a significant impact on cognitive and neural motor development $(11,12)$. Supplements containing iron have been used effectively as a solution for this problem. However, due to teeth staining in children after taking iron drops, parents are of the view that iron drops are the cause of tooth decay and therefore limit iron supplements in their children's diet (6).

The results of the current study indicate that there is no harmful effect of iron supplementation therapy to the primary teeth. On the contrary, although it is not statistically significant probably because of the low study population, it seems that there may be a protective effect of iron therapy for tooth decay. In the animal studies on this subject, it is suggested in a way supporting our hypothesis that when iron containing supplements are used, despite some side effects such as teeth discoloration, reduction of dental caries progression is expected when the cariogenic dietary regimen is used (6). The ability of $\mathrm{Fe}$ to reduce enamel demineralization has already been demonstrated and confirmed by in situ studies (13-15).

It was shown that rats fed with an irondeficient diet who had severe nutritional ferropenic anemia causes a reduction of bone calcium, which then results in a significant modification in the metabolism of magnesium and calcium (16). Moreover, there was a significant reduction of enamel pigmentation and sections of the incisors showed enamel hypoplasia and aplasia (16).

Iron is incorporated into ameloblasts and then into the outer layer of enamel which results in a zone of high iron content (17). It has been shown that rats suffer several abnormalities such as, significant loss of enamel pigmentation, aplasia and enamel hypoplasia due to iron deficiency (16).

Studies on rats have shown that co-crystallized iron (Fe-sucrose) in the form of sucrose is markedly less cariogenic compared with pure sugar (18). Furthermore, iron supplements in sucrose have been used successfully to reduce anemia caused by iron deficiency. Thus, potentially two of the most prevalent diseases could be mitigated by adding iron to sugar (13). 
The mechanism of how Fe exerts its cariostatic effects has not been definitely discovered. However, there are several possibilities and include the following: (i) decreased enamel solubility in acids; (ii) reducing dental plaque acidogenicity; (iii) a bactericidal and bacteriostatic effect on oral streptococci; or (iv) reduction in glucosyltransferases activity of mutans streptococci (13).

In a study by Niedzielska et al, the carietic primary teeth contained less $\mathrm{Mg}, \mathrm{Fe}, \mathrm{Sr}, \mathrm{Ni}, \mathrm{Mn}$ and $\mathrm{Cu}$ and much more $\mathrm{Zn}$ as compared to teeth without caries (19). In a way supporting this hypothesis, there was a negative, but not significant correlation between the iron concentration in the primary teeth and the DMFT score in this study.

In a more recent study an comparable compelling relationship between excessive caries during childhood and low ferritin was found (20). The researchers also found that these children also had significantly lower levels of hemoglobin and iron than the control group (20). Thus, both of these studies propose a relationship between overall iron levels and S-ECC.

Teeth stains in young children can come from a variety of sources. Juices, medicines, vitamins, even a harmless naturally occurring colored bacteria can all cause stains to form along the teeth and gum line. The liquid form of iron can also stain the teeth, which is a side effect not recognized with other forms of iron supplements. To prevent liquid iron staining teeth, it should be mixed with juice or water and a straw can also assist in keeping the liquid iron away from teeth. If using a dropper, it should be placed on the back of the tongue. Iron stains on teeth can be removed by brushing with baking soda or medicinal-strength hydrogen peroxide because iron stains are temporary (21).

\section{Conclusions}

If the physicans giving iron therapy for supplementation inform and encourage the parents in this way, the deprivation of this vital supplement because of misconceptions/fallacies can be prevented.

Ethical Approval: Ethics committee approval was received for this study Institutional Ethical Committee and Central Ethics Committee on Human Research.

Peer-review: Externally peer-reviewed.

Author Contributions: Conception E.A.M., İ.E.; Design - E.A.M., O.E.; Supervision-I.E.; Materials -E.A.M., Data Collection and/or Processing-i.E., O.E.; Analysis and/or Interpretation - E.A.M., Literature Review - E.A.M., Writer-E.A.M, Critical Review-I.E, O.E.

Conflict of Interest: No conflict of interest was declared by the authors.

Financial Disclosure: The authors declared that this study has received no financial support.

\section{References}

1. Grantham-McGregor S, Ani C. A review of studies on the effect of iron deficiency on cognitive development in children. J Nutr 2001; 131: 649-66. (Crossref)

2. Dewey KG, Chaparro CM. Session 4: Mineral metabolism and body composition iron status of breast-fed infants. Proc Nutr Soc 2007; 66: 412-22. (Crossref)

3. Health Canada, Canadian Paediatric Society, Dietitians of Canada, Breastfeeding Committee for Canada. Nutrition for healthy term infants: recommendations from birth to six months. Can J Diet Pract Res 2012;73:204. (Crossref)

4. Eidelman Al. Breastfeeding and the use of human milk: an analysis of the American Academy of Pediatrics 2012 Breastfeeding Policy Statement. Breastfeed Med 2012;7:23-4. (Crossref)

5. Talebi M, Parisay I, Mokhtari N. The parents' knowledge and behavior towards the effects of using iron supplements on tooth staining and dental caries in Mashhad, Iran. Dent Res J (Isfahan) 2012;9:715-8.

6. Eshghi A, Kowsari-Isfahan R, Rezaiefar M, et al. Effect of iron containing supplements on rats' dental caries progression. $J$ Dent (Tehran) 2012;9:14-9.

7. Sintes JL, Miller SA. Influence of dietary iron on the dental caries incidence and growth of rats fed an experimental diet. Arch Latinoam Nutr 1983;33:322-38.

8. Emilson CG, Krasse B. The effect of iron salts on experimental dental caries in the hamster. Arch Oral Biol 1972; 17: 1439-43. (Crossref)

9. Miguel JC, Bowen WH, Pearson SK. Effects of iron salts in sucrose on dental caries and plaque in rats. Arch Oral Biol 1997;42:377-83. (Crossref)

10. Domellöf $M$, Braegger C, Campoy C, et al.; ESPGHAN Committee on Nutrition. Iron requirements of infants and toddlers. J Pediatr Gastroenterol Nutr 2014;58:119-29. (Crossref)

11. Baker RD, Greer FR; Committee on Nutrition American Academy of Pediatrics. Diagnosis and prevention of iron deficiency and iron-deficiency anemia in infants and young children (0-3 years of age). Pediatrics 2010;126:1040-50. (Crossref)

12. Lozoff B, Jimenez E, Wolf AW. Long-term developmental outcome of infants with iron deficiency. N Engl J Med 1991; 325: 687-94. (Crossref)

13. Pecharki GD, Cury JA, Paes Leme AF, et al. Effect of sucrose containing iron (II) on dental biofilm and enamel demineralization in situ. Caries Res 2005;39:123-39. (Crossref)

14. Martinhon CC, Italiani Fde M, Padilha Pde M, et al. Effect of iron on bovine enamel and on the composition of the dental biofilm formed "in situ". Arch Oral Biol 2006;51:471-5. (Crossref)

15. Sales-Peres SH, Pessan JP, Buzalaf MA. Effect of an iron mouthrinse on enamel and dentine erosion subjected or not to abrasion: an in situ/ex vivo study. Arch Oral Biol 2007;52:128 32. (Crossref)

16. Morohashi T, Hirama $\mathrm{Y}$, Takahara S, et al. Defects in mandibular bone area, enamel iron content and dentine formation following gastrectomy in rats. Arch Oral Biol 2002;47:499-504. (Crossref)

17. Halse A, Selvig KA. Incorporation of iron in rat incisor enamel. Scand J Dent Res 1974; 82: 47-56. (Crossref)

18. Rosalen PL, Pearson SK, Bowen WH. Effects of copper, iron and flüoride co-crystallized with sugar on caries development and acid formation in deslivated rats. Arch Oral Biol 1996;41:1003 10. (Crossref)

19. Niedzielska K, Struzak-Wysokińska M, Wujec Z. Analysis of correlations between the content of various elements in hard 
tissues of milk teeth with and without caries. Czas Stomatol 1990;43:316-22.

20. Shaoul R, Gaitini L, Kharouba J, et al. The association of childhood iron deficiency anaemia with severe dental caries. Acta Paediatr 2012;101:76-9. (Crossref)
21. Pani SC, Alenazi FM, Alotain AM, et al. Extrinsic tooth staining potential of high dose and sustained release iron syrups on primary teeth. BMC Oral Health 2015;15:90. (Crossref) 